\title{
Schüler-Seminar 2010
}

HERBERT BILLENSTEINER

Zum Schüler-Seminar 2010, das bereits zum 28. Mal von der Gesellschaft der Freunde des Palmengartens e.V. durchgeführt wurde, waren 49 Teilnehmerinnen und Teilnehmer angemeldet.

Ziel des Schülerseminars war es, durch Beschäftigung mit Pflanzen und ihrem Wachstum das Interesse an Natur und Umwelt zu wecken und zu fördern. Zum Thema „Kräuter und Gewürze" lernten die Kinder an sechs Samstagen unter Leitung von UTE KÖLLEN, AsTRID STEINDORF und BEATE VAUPEL heimische und tropische würzige Pflanzen kennen.

Einige dieser Pflanzen wurden von der Aussaat bis zu ihrer Verwendung erkundet. Die Kinder pflanzten während des ersten SeminarTermins im April Paprika in Töpfe, die sie mit nach Hause nahmen. Zum letzten Treffen im Oktober brachten sie diese wieder mit. Die größten Pflanzen wurden durch Buchpreise, gespendet von der Firma Hugendubel, prämiert. Hierfür bedanken wir uns sehr herzlich.

Die größte Paprika-Pflanze war gut $60 \mathrm{~cm}$ hoch und ebenso breit. Alle Teilnehmerinnen und Teilnehmer erhielten eine PalmengartenBastelmappe. Die Teilnehmerin ElAINE ARCHONTI-BÜCHNER äußerte sich über das Schüler-Seminar: „Nun nehme ich schon seit zwei Jahren an Schüler-Seminaren teil. Das Seminar im letzten Jahr hatte das Thema „Farben in der Natur". Es war interessant, was wir dort lernten, z. B. wie man Lebensmittel färbt, welches die Regenbogenfarben sind. Wir experimentierten mit Pflanzenfarben. In diesem Jahr war das Thema „Kräuter und Gewürze“. Wir haben

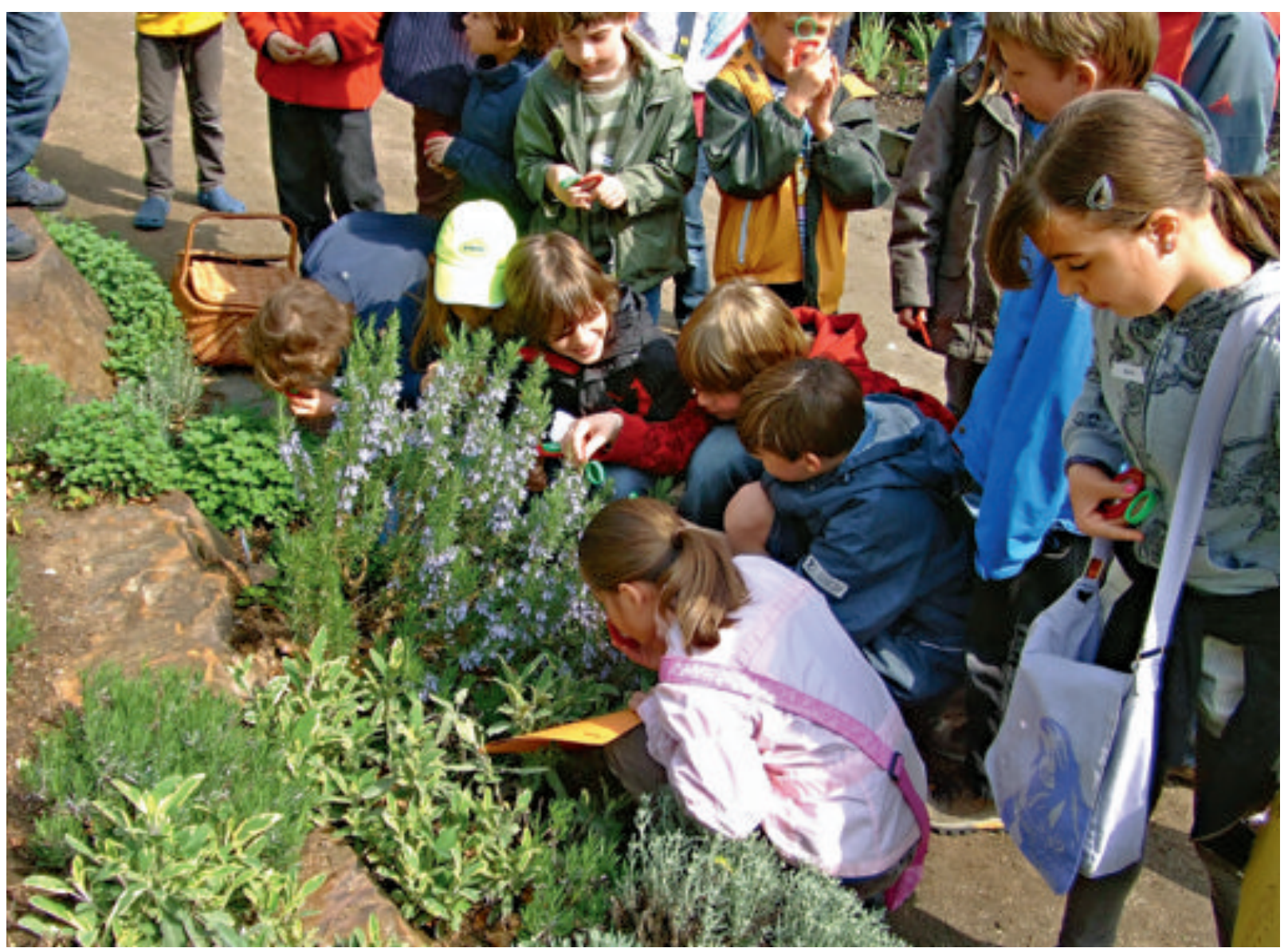




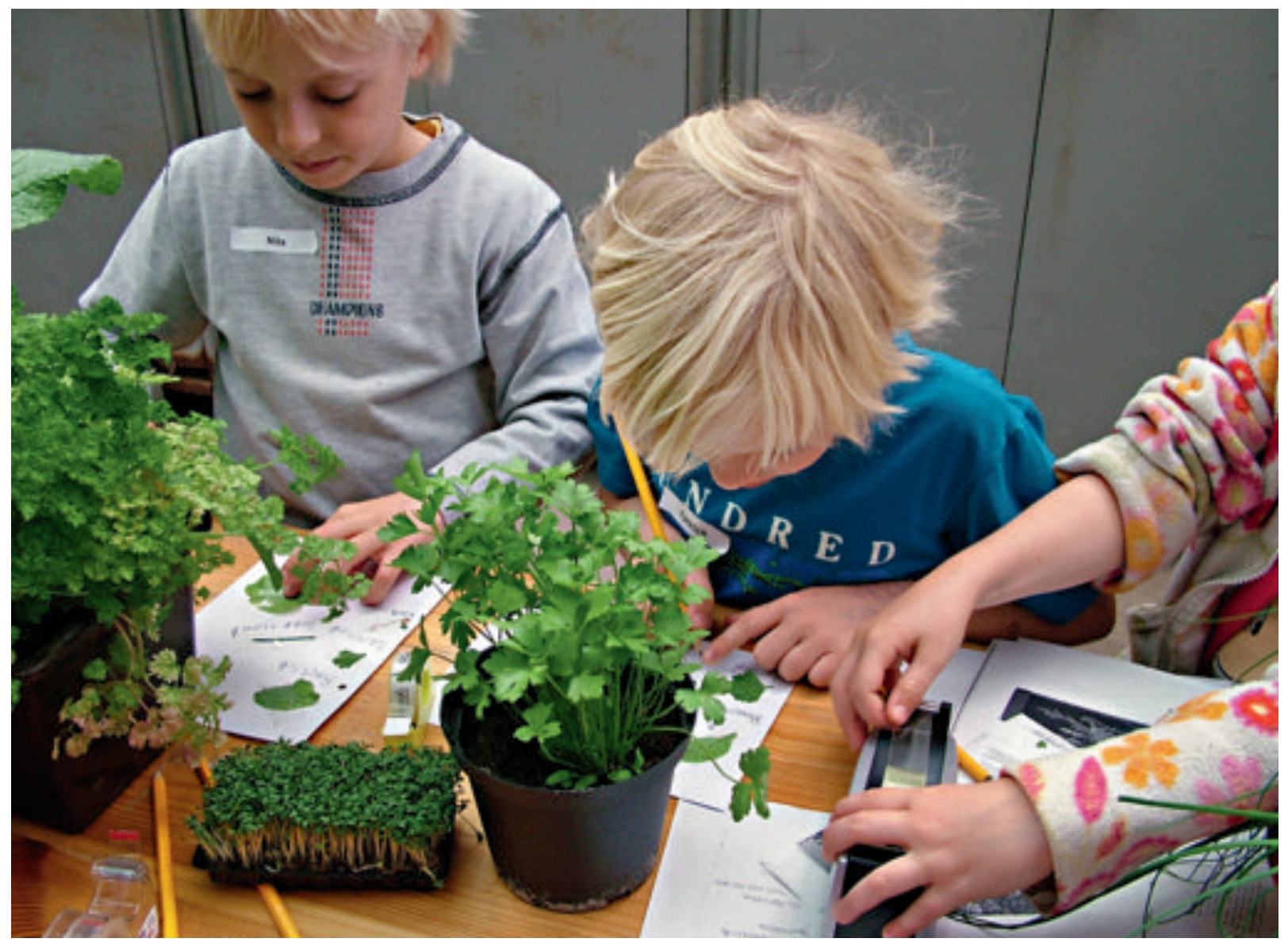

Samen ausgesät und vereinzelt eingepflanzt, einmal haben wir selber "Grüne Soße“ gemacht und mit Ei und Brot gegessen. Wir experimentierten mit verschiedenen Gewürzen. Am Beginn eines Seminares pflanzten wir Pflegepflanzen ein, letztes Jahr eine Buntnessel, dieses Mal eine Paprikapflanze, die am Ende des Seminars bewertet wurde. Empfehlen würde ich die Seminare allen Kindern zwischen 6 und 10 Jahren. Die Seminar-Leiterinnen sind alle sehr nett und erzählen viele interessante Dinge. Ein sehr interessanter Workshop.“

Abb. 1 (S. 152): Kinder erkunden Gewürz-Kräuter.

Abb. 2 (oben): Verschiedene Gewürzpflanzen werden untersucht und gezeichnet.

Abb. 3 (unten): Workshop in der Gärtnerei des Palmengartens.

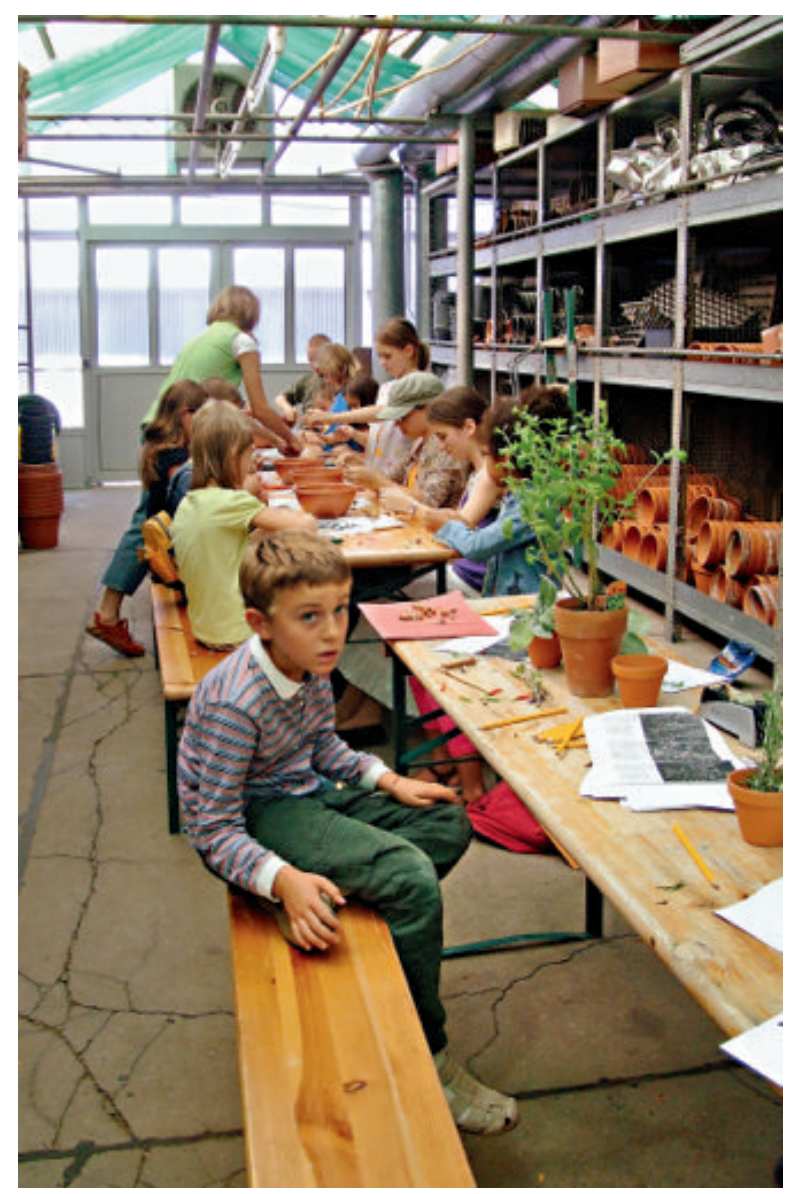

